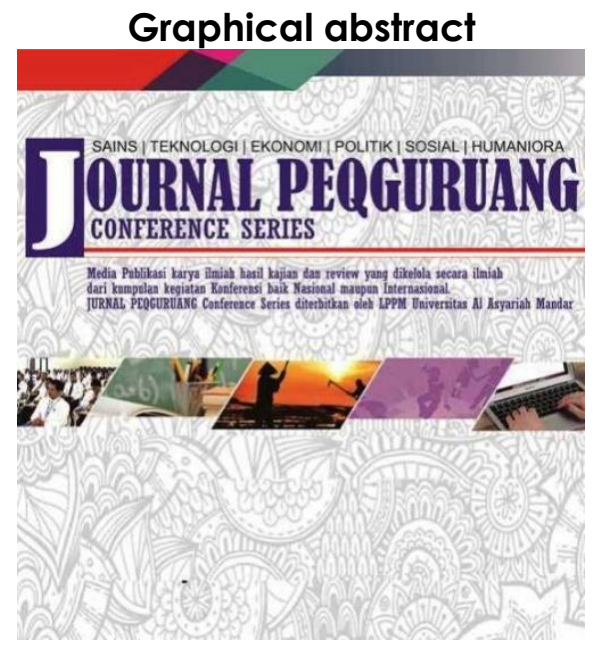

\title{
PERAN PEMERINTAH TERHADAP PENGELOLAAN ARSIP DI KANTOR DINAS PERPUSTAKAAN DAN KEARSIPAN KABUPATEN POLEWALI MANDAR
}

\author{
${ }^{1}$ A. Sari Indra Dewi, ${ }^{2}$ Rustan IR, ${ }^{3}$ Mukhlis Hannan \\ Program Ilmu Pemerintahan, Fakultas Pemerintahan, \\ Universitas Al Asyariah Mandar \\ 1andisariindradewi70@gmail.com \\ 2rustam.irta17@gmail.com \\ ${ }^{3}$ mukhlishannan49@gmail.com
}

\begin{abstract}
The study aims to find out how the Government's Role in Archive Management in the Polewali Mandar District Library and Archives Service and to find out how the Archive management system is for achieving administrative order in the Polewali Mandar District Library and Archives Office.

Research informants namely: Head of Office as Key Informant, Head of Archives, Head of Archives Development Section, Head of Archive Management Section, and Archive Management Staff.

The results obtained from the study show the role of government in the management of archives in the Polewali Mandar District Library and Archives Office less attention from the government due to lack of budget in the last few years so there is not much activity for the library, especially the management and improvement of archives43, the administrative process goes well according to the rules, clarification of the archive and staffing rules, some filing processes are in accordance with PP number 43 of 2009 and have long been applied in the office the archive space is not adequate because many archives are stacked on the table, cupboard and not stored on a file rack, archive management using a manual system every file that enters the computer.

Keywords: Role, Government, Archives
\end{abstract}

\begin{abstract}
Abstrak
Penelitian bertujuan mengetahui bagaimana Peran Pemerintah Terhadap Pengelolaan Arsip diDinas Perpustakaan dan Kearsipan kabupaten Polewali Mandar dan mengetahui bagaimana sistem pengelolaan Arsip demi tercapainya tertib administrasi diKantor Dinas Perpustakaan dan Kearsipan Daerah Kabupaten Polewali Mandar.

Informan penelitian yakni: Kepala Dinas Selaku Informan Kunci, Kepala Bidang Kearsipan, Keapala Seksi Pembinaan Arsip, Kepala Seksi Pengelolaan Arsip, beserta Staf Pengelolaan Arsip.

Hasil diperoleh dari penelitian menunjukkan Peran pemerintah terhadap pengelolaan arsip diKantor Perpustakaan dan Kearsipan Kabupaten Polewali Mandar kurang perhatian dari pemerintah karena kurangnya anggaran beberapa tahun terakhir jadi tidak banyak kegiatan untuk perpustakaan terutama pengelolaan dan pembenahan kearsipan43, Proses administrasi berjalan baik sesuai dengan aturan, klarifikasi arsip dan aturan kepegawaian, beberapa proses kearsipan sudah sesuai dengan PP nomor 43 tahun 2009 dansudah lama diterapkan dikantor tersebut ruang arsip belum memadai karna banyak arsip ditumpuk diatas meja, lemari dan tidak disimpan pada rak arsip, Pengelolaan arsip menggunakan sistem manual setiap arsip yang masuk kedalam komputer.
\end{abstract}

Kata Kunci :Peran, Pengelolaan, Arsip dan Kearsipan

\section{Article history}

DOI: http://dx.doi.org/10.35329/ip.v2i2.1575

Received : 07 September 2020 | Received in revised form : 17 September 2020 | Accepted : 03 Oktober 2020 


\section{PENDAHULUAN}

Teknologi yang berkembang pada saat sekarang sudah semakin menuntut betapa pentingsuatu informasi untuk setiap organisasi/instansi baik pemerintah maupun swasta. Pada dasarnya seluruh kegiatan organisasi/instansi baik itu instansi pemerintah ataupun swasta sangat butuh informasi sebagai salah satu pendukung proses kerja administrasi dan untuk pelaksanaan fungsi manajemen. Organisasi/instansi baik pemerintah ataupun swasta memerlukan pengendalian manajemen untuk memberikan jaminan dilaksanakannya strategi organisasi secara efektif dan efisien, sehingga tujuan organisasi dapat dicapai.

Dalam organisasi, informasi menjadi kebutuhan mutlak, menjadi salah satu sumber informasi yang dapat menunjang suatu proses kegiatan administrasi itu adalah arsip. Arsip adalah suatu pusat ingatan, informasi dan juga alat bukti tertulis yang melancarkan kegiatan organisasi. Arsip merupakan bukti bahwa suatu peristiwa telah terjadi. Tanpa arsip, sulit sekali membuktikan sesuatu hal atau mengingat-ingat kejadian di masa lampau. Informasi yang terkandung dalam arsip apabila tersedia pada waktu diperlukan, maka akan melancarkan kegiatan organisasi (Syaeba, M, 2019). Untuk itu, perlu adanya pengelolaan arsip yang efektif dan efisien sehingga memudahkan bagi pihak yang membutuhkan.

Menurut undang-undang nomor 43 tahun 2009 arsip ialah rekaman suatu kegiatan atau peristiwa dalam berbagai macam bentuk dan sesuai dengan perkembangan teknologi saat ini informasi dan komunikasi yang dibuat dan diterima oleh lembaga negara, pemerintahan daerah, lembaga pendidikan, perusahaan, organisasi politik, organisasi kemasyarakan, dan perseoragnan dalam kehidupan bermasyarakat, berbangsa, dan bernegara. (http://www.duniaarsip.com)

Kantor Dinas Perpustakaan dan Kearsipan Kabupaten Polewali Mandar yang dibawah struktur pemerintah Kabupaten Polewali Mandar sangat berkepentingan dalam mempunyai relevansi langsung dalam menterjemahkan seluruh fenomena perkembangan maupun perubahan dalam penyelenggaraan pemerintah tersebut, melalui bentuk laporan keterangan pertanggungjawaban Kantor Perpustakaan dan Kearsipan Daerah Kabupaten Polewali Mandar secara Proposional dan Inplementatif.

Kantor Dinas Perpustakaan dan Kearsipan Kabupaten Polewali Mandar memiliki fungsi yaitu bertanggung jawab sebagai pengelola Perpustakaan dan Arsip daerah. Kantor Dinas Perpustakaan dan Kearsipan Kabupaten Polewali Mandar merupakan lembaga dari gabungan Kantor Perpustakaan Umum Daerah dan Kantor Arsip Daerah Kabupaten Polewali Mandar.

Dalam instansi pemerintahan kebanyakan data berkas laporan tidak tersusun dengan baik, sehingga metode pencarian data untuk pelaporan terkadang mendapat suatu masalah yang membuat suatu instansi pemerintah terkhusus bagian pengarsipan terlalu sibuk mengurus data-data arsip setiap instansi pemerintahan begitupun yang saat ini terjadi pada Kantor Dinas Perpustakaan dan Kearsipan kabupaten Polewali Mandar, dimana setiap arsip yang masuk dari instansi lain datanya dikelola secara manual, kurang teraturnya penyimpanan arsip, kurangnya sarana dan prasarana antara lain lemari arsip dan rak-rak penyimpanan arsip penempatan arsip yang belum memadai karena ada beberapa arsip yang tersimpan diatas lemari dan sehingga proses pencarian arsip baik yang baru masuk maupun arsip yang sudah lama mendapat suatu permasalahan dengan mengkoordinasikan waktu pada proses pencarian dalam kata lain kurangnya pegefisiensian waktu. Oleh sebab itu, peneliti ingin meneliti bagaimana "Peran Pemerintah Terhadap Pengelolaan Arsip Pada Dinas Perpustakaan dan Kearsipan Kabupaten Polewali Mandar”.

\section{METODE PENELITIAN}

Dalam Penelitian ini, penulis dapat menggunakan pendekatan kualitatif. Bogdan dan taylor menyatakan bahwa "metodologi kualitatif" sebagai prosedur penelitian yang menghasilkan data deskriptif berupa kata-kata tertulis atau lisan dari orang-orang dan perilaku yang dapat diamati. Dengan pendekatan kualitatif, akan memberikan gambaran mengenai bagaimana peran pemerintah terhadap pengelolaan arsip di kantor Dinas Perpustakaan dan Kearsipan Kabupaten Polewali Mandar.

Adapun alasan memilih objek lokasi penelitian tersebut adalah untuk mengetahui tentang pengelolaan arsip dan kearsipan khususnya di Polewali Mandar yang pengelolaannya dijalankan oleh Kantor Dinas Perpustakaan dan Kearsipan Polewali Mandar.Adapun waktu penelitian yang akan dilaksanakan pada bulan April 2020 sampai selesai dan tentunya setelah mendapat surat izin penelitian. Hal ini diperlukan untuk lebih mempertajam analisis terhadap masalah yang diteliti secara teoritis sehingga dengan waktu tersebut cukup maksimal oleh kandidat dalam menyelesaikan penelitian sekaligus proses penulisannya.

Beberapa responden dalam penelitian tentang Peran Pemerintah Terhadap Pengelolaan Arsip di Kantor Dinas Perpustakaan dan Kearsipan Kabupaten Polewali Mandar terdiri dari Kepala Bidang, Kepala Dinas, Para Pegawai yang berjumlah 5 Orang.

Dalam penelitian yang dilakukan peneliti, peneliti menggunakan beberapa teknik pengumpulan data. Adapun data yang diperoleh dalam penelitian ini bersumber pada data:

1.Data primer

Data primer adalah data yang diperoleh secara langsung dari lapangan, teknik pengumpulan data uang digunakan berupa observasi dan wawancara.

a) Observasi

Observasi merupakan teknik pengumpulan data yang dilakukandengan cara melakukan pengamatan dan pencatatan secara sistematik terhadap suatu gejala yang tampak pada objek penelitian. Objek dari 
observasi ini adalah Dinas Perpustakaan dan Kearsipan Kabupaten Polewali Mandar, pengamatan yang dilakukan adalah dengan melihat dan mengamati langsung pelaksanaan pengelolaan arsip, mengumpulkan fakta-fakta dan pernyataan untuk dibahas dalam penelitian.

b) Wawancara

Wawancara adalah suatau proses tanya jawab lisan, dimana 2 orang atau lebih saling berhadapan secara fisik, yang satu dapat melihat muka lain dan mendengar dengan telinga sendiri dari suaranya (Sukandarrumidi, 2006: 89). Wawancara adalah proses Tanya jawab sambil bertatap muka antara pewawancara dan informan bertujuan untuk memperoleh keterangan untuk tujuan penelitian, dengan atau tanpa menggunakan pedoman wawancara, dimana informan dan pewawancara terlibat dalam kehidupan sosial yang relatif lama. Bentuk wawancara yang digunaka peneliti adalah wawancara yang tidak terstruktur, wawancara dilakukan untuk mwndapatkan hasil observasi awal dan nebjawab rumusan masalah mengenai peran pemerintah terhadap pengelolaan arsip di Kantor Dinas Perpustakaan dan Kearsipan Kabupaten Polewali Mandar.

2.Data Sekunder

Sekunder adalah data yang diperoleh dari sumber-sumber yang telah ada. Peneliti mengumpulkan data melalui teknik, studi pustaka. Sumber data dapat diperoleh melalui., buku, artikel jurnal, halaman website, laporan penelitian dan lainnya, dan melalui dokumentasi.

\section{a) Studi pustaka}

Studi pustaka adalah kumpulan data yang dilakukan dengan mencari sumber data tertulis seperti buku, artikel jurnal dan laporan penelitian terdahulu yang dapat dijadikan landasan teori untuk memperkuat proses analisis data.

b) Dokumentasi

Dokumentasi adalah pengumpulan data yang mengandunginformasi dari objek penelitian agar dapat membantu peneliti, baik dari sumber yang berbentuk tulisan seperti kebijakan, catatan harian, atau sumbersumber yang berbentuk gambar seperti foto dan lainlain. Data dokumentasi yang digunakan untuk memperoleh data yang nyata yang dijadikan sebagai objek penelitian yaitu tentang peran pemerintah terhadap pengelolaan arsip di Kantor Dinas Perpustakaan dan Keasipan kabupaten Polewali Mandar.

Dalam pengumpulan data, peneliti menggunakan metode sebagai berikut:

Observasi (Pengamatan), yaitu penulis melakukan penelitian dalam arti mengamati dan melakukan pencatatan mengenai fenomena atau aktifitas yang menjadi berkaitan dengan pembahasan skripsi ini.

a) Wawancara (interview) dalam hal ini peneliti mengadakan Tanya jawab dan bertatap muka langsung dengan arsiparis yang berkaitan dengan permaslahan yang diteliti, metode ini bertujuan untuk mendapatkan data yang semaksimal mungkin efektif informadinya.

b) Dokumentasi, merupakan metode yang digunakan hal-hal atau variable yang digunakan berupa catatan, transkip, surat kabar, prasasti, notulen rapat, lengger, agenda dan sebagainya.

c) Tape record yaitu alat yang akan peneliti gunakan untuk merekam percakapan saat melakukan wawancara sehingga informasi yang diberikan oleh informan menjadi lebih akurat dan objektif. Dalam hal ini peneliti akan menggunakan handphone smartphone android untuk merekam pwecakapan tersebut

Setelah semua data terkumpul maka dilakukan analisa data, yaitu memilih hal-hal pokok, memfokuskan pada hal-hal yg penting untuk dicari. Proses analisis dapat dilakukan dalam tiga tahap yaitu:

a) Reduksi data (data reduction)

Data yang diperoleh dari lapangan melalui observasi, wawancara, dokumentasi dan tape record yang jumlahnya cukup banyak peneliti mencatat dengan rinci, kemudian dilakukan perangkuman. Dengan demikian data yang telah direduksi dapat memberikan gambaran penerapan manajemen kearsipan.

b) Penyajian data (data display)

Setelah reduksi data, langkah selanjutnya adalah penyajian data. Menyajikan data dalam bentuk deskriftif dapat memberikan gambaran penerapan manajemen kearsipan.

c) Penarikan kesimpulan (verification)

Data-data yang telah diterangkan dan dijabarkan dalam bentuk narasi kemudian penulis gunakan untuk menjawab masalah yang telah dirumuskan sejak awal.

\section{HASIL DAN PEMBAHASAN}

Adapun data dari hasil penelitian yang dilakukan secara langsung di Kantor Dinas Perpustakaan dan Kearsipan Kabupaten Polewali Mandar dengan cara melakukan wawancara dan memberikan kuisioner kepada informan.

Berikut Daftar Data - Data Arsip Di Kantor Dinas Perpustakaan dan Kearsipan Kabupaten Polewali Mandar Terhitung tahun 2019. 
Data Daftar Objek Binaan Arsip

Kabupaten Polewali Mandar Tahun 2019

\begin{tabular}{|c|c|c|c|}
\hline $\mathrm{NO}$ & $\begin{array}{c}\text { Nama Instansi } \\
\text { Pemerintah/Swasta }\end{array}$ & $\begin{array}{c}\text { SK Bupati. } \\
\text { Surat } \\
\text { Edaran, } \\
\text { Surat Masuk } \\
\text { dan Surat } \\
\text { Keluar) } \\
\end{array}$ & Ket \\
\hline 1 & Dpmptsp & 13 & \\
\hline 2 & Disdukcapil & 5 & \\
\hline 3 & $\begin{array}{l}\text { Dinas Pertanian dan } \\
\text { Ketahanan Pangan }\end{array}$ & 3 & \\
\hline 4 & $\begin{array}{l}\text { Badan Keuangan dan } \\
\text { Aset daerah (BPKAD) }\end{array}$ & 18 & \\
\hline 5 & Dinas Perhubungan & 90 & \\
\hline 6 & $\begin{array}{c}\text { Dinas Lingkungan } \\
\text { Hidup dan Kehutanan }\end{array}$ & 40 & \\
\hline 7 & Kecamatan Binuang & - & \\
\hline 8 & Kecamatan Polewali & - & \\
\hline 9 & Kecamatan Matakali & 30 & \\
\hline 10 & $\begin{array}{l}\text { Kecamatan } \\
\text { Wonomulyo }\end{array}$ & 33 & \\
\hline 11 & Kecamatan Tapango & 1 & \\
\hline 12 & Kecamatan Anreapi & 10 & \\
\hline 13 & $\begin{array}{l}\text { Kecamatan } \\
\text { Campalagian }\end{array}$ & 80 & \\
\hline 14 & Kecamatan Limboro & 45 & \\
\hline 15 & Kecamatan Tinambung & 17 & \\
\hline 16 & Kecamatan Mapilli & 7 & \\
\hline 17 & Kecamatan Luyo & 56 & \\
\hline 18 & Kecamatan Alu & 3 & \\
\hline 19 & Kecamatan Balanipa & 14 & \\
\hline 20 & Kecamatan Bulo & 2 & \\
\hline
\end{tabular}

Adapun data sosialisasi dan peningkatan SDM pengelolaan Kearsian Kabupaten Polewali Mandar pada tahun 2019 pada intansi pemerintahan.

Pada tahun 2019 hanya ada 6 (Enam) OPD dan 12 (Dua Belas) Kecamatan yang menyetorkan Arsip ke Kantor Dinas Perpustakaan dan Kearsipan Kabupaten Polewali Mandar. Berikut uraiannya:

\begin{tabular}{lllll}
\hline NO. & $\begin{array}{l}\text { Instansi } \\
\text { Pemerintaha } \\
\mathrm{n}\end{array}$ & $\begin{array}{l}\text { Ju } \\
\text { mla } \\
\mathrm{h}\end{array}$ & $\begin{array}{l}\text { Kurun } \\
\text { Waktu }\end{array}$ & $\begin{array}{c}\text { Tingkat } \\
\text { Perkembanga } \\
\text { n (Copy Asli, } \\
\text { Pertinggal) }\end{array}$ \\
\hline & $\begin{array}{l}\text { Badan } \\
\text { Pengelola } \\
\text { Keuangan } \\
\text { \& Aset }\end{array}$ & 18 & 1 Tahun & Copy \\
& $\begin{array}{l}\text { Daerah } \\
\text { Dpmptsp } \\
\text { Dinas } \\
\text { Perhubungan }\end{array}$ & 12 & 1 Tahun & Copy \\
& 90 & 1 Tahun & Copy \\
4 & $\begin{array}{l}\text { Dinas } \\
\text { Lingkungan }\end{array}$ & 40 & 1 Tahun & Copy \\
& Hidup & & &
\end{tabular}

\begin{tabular}{|c|c|c|c|c|}
\hline 5 & $\begin{array}{l}\text { Dinas } \\
\text { Pertanian }\end{array}$ & 3 & 1 Tahun & Copy \\
\hline 6 & $\begin{array}{l}\text { Dinas } \\
\text { Kependuduka } \\
\text { n \& Catatan } \\
\text { Sipil }\end{array}$ & 15 & 1 Tahun & Copy \\
\hline 7 & $\begin{array}{l}\text { Kecamatan } \\
\text { Anreapi }\end{array}$ & 10 & 1 Tahun & Copy \\
\hline 8 & $\begin{array}{l}\text { Kecamatan } \\
\text { Tinambung }\end{array}$ & 18 & 1 Tahun & Copy \\
\hline 9 & $\begin{array}{l}\text { Kecamatan } \\
\text { Matakali }\end{array}$ & 30 & 1 Tahun & Copy \\
\hline 10 & $\begin{array}{l}\text { Kecamatan } \\
\text { Campalagian }\end{array}$ & 80 & 1 Tahun & Copy \\
\hline 11 & $\begin{array}{l}\text { Kecamatan } \\
\text { Mapilli }\end{array}$ & 7 & 1 Tahun & Copy \\
\hline 12 & $\begin{array}{l}\text { Kecamatan } \\
\text { Balanipa }\end{array}$ & 12 & 1 Tahun & Copy \\
\hline 13 & $\begin{array}{l}\text { Kecamatan } \\
\text { Tapango }\end{array}$ & 1 & 1 Tahun & Copy \\
\hline 14 & $\begin{array}{l}\text { Kecamatan } \\
\text { Alu }\end{array}$ & 3 & 1 Tahun & Copy \\
\hline 15 & $\begin{array}{l}\text { Kecamatan } \\
\text { Limboro }\end{array}$ & 45 & 1 Tahun & Copy \\
\hline 16 & $\begin{array}{l}\text { Kecamatan } \\
\text { Bulo }\end{array}$ & 2 & 1 Tahun & Copy \\
\hline 17 & $\begin{array}{l}\text { Kecamatan } \\
\text { Wonomulyo }\end{array}$ & 33 & 1 Tahun & Copy \\
\hline 18 & $\begin{array}{l}\text { Kecamatan } \\
\text { Luyo }\end{array}$ & 53 & 1 Tahun & Copy \\
\hline
\end{tabular}

Sumber: Dinas Perpustakaan dan Kearsipan Kabupaten Polewali Mandar

a. Peran

Peran adalah aspek dinamis dari kedudukan atau status. Peran adalah gambaran sosial tentang siapa kita ini, peran juga mempunyai makna ketika dikaitkan dengan orang lain, komunitas sosial atau politik. Peran juga diartikan sebagai kombinasi, posisi dan pengaruh. Seseorang melaksanakan hak dan kewajiban, berarti telah menjalankan suatu peran.

Peran menurut Soekanto (2009:212-213) adalah proses dinamis kedudukan apabila seseorang melaksakan kewajiban dan hak itu sesuai dengan kedudukannya, dan itu

yang dinamakan menjalankan suatu peranan. Kedudukan sebagai suatu tempat atau jabatan yang dimiliki oleh seseorang dalam kehidupan sosial berbangsa dan bernegara untuk kepentingan ilmu pengetahuan.

Peranan pemerintah diartikan sebagai organisasi bagian atau pemegang pimpinan, wewenang dan kekuasaan yang mengatur kehidupan sosial, ekonomi, dan politik suatu Negara. Saat ini peran pemerintah terhadap pengelolaan arsip sangat kurang kenapa demikian karna kurangnya anggaran untuk bidang kearsipan itu sendiri. Setiap kegiatan maupun rencana memerlukan anggaran. Berdasarkan hasil wawancara dengan Bapak Drs. H. Andi Amrin, MM 
selaku Kepala Dinas Perpustakaan dan Kearsipan, berikut kutipan wawancaranya:

"bahwa menurutnya, adalah kurangnya anggaran terhadap pengelolaan arsip menjadi kendala bagi setiap kegiatan kearsipan Masih sangat kurang karna untuk saat ini tidak anggaran dari pemda untuk pembenahan perpustakaan dan bagian pengelolaan kearsipan itu sendiri padahal semua harus sesuai dengan anggaran daerah, sehingga tidak banyak kegiatan dan pembenahan untuk kearsipan di kantor ini" (Wawancara, tanggal 20 April 2020)

b. Pengelolaan

Pengelolaan diartikan sebagai suatu rangkaian pekerjaan atau usaha yang dilakukan oleh sekelompok orang untuk melakukan serangkaian kerja dalam mencapai tujuan tertentu, define pengelolaan para ahli terdapat perbedaan-perbedaan hal ini disebabkan para ahli meninjau pengertian dari sudut yang berbedabeda.Menurut Adisasmita pengelolaan bukan hanya melaksanakan suatu kegiatan, akan tetapi merupakan rangkaian kegiatan yang meliputi fungsi-fungsi manajemen seperti perencanaan, pelaksanaan dan pengawasan untuk mencapai tujuan secara efektif dan efisien.

Kantor Dinas Perpustakaan dan Kearsipan Kabupaten Polewali Mandar sebagai pusat pengumpalan arsip dari 16 Kecamatan dan 28 OPD. Setiap bulan akan di surati oleh bagian kearsipan untuk mengumpulkan arsip yang ada di setiap kecamatan dan OPD di kabupaten Polewali Mandar. Pengelolaan arsip di kantor dinas perpustakaan dan kearsipan kabupaten polewali mandar sudah baik dan tepat tapi ada beberapa yang menjadi kendala dalam pengelolaannya. Pertama masalah kekurangan anggaran yang masih sampai saat ini tidak ada kemajuan sehingga pembenahan dan perbaikan pengelolaan arsip tidak dilakukan, Masalah tempat/ruang penyimpanan arsip yang kurang memadai dan sempit, sarana dan prasarana yang kurang seperti rak-rak arsip dan lemari arsip sehingga masih banyak arsip yang tidak tersusun rapih pada tempatnya bahkan banyak ditemukan arsip yang bertumpuk diatas meja dan diluar ruang penyimpanan arsip. Kedua tentang sistem pengelolaan arsip demi tercapainya tertib administrasi dikantor ini juga sudah baik, tapi perlu tenaga khusus / ahli tentang kearsipan agar bisa lebih efektif dalam tercapainya tertib administrasi.

Pengelolaan arsip di kantor dinas perpustakaan dan arsipan kabupaten polewali mandar sudah sesuai dengan aturan yang berlaku pada peraturan pemerintah nomo 43 tahun 2009, tetapi pengelolaannya masih menggunakan pengelolaan manual sehingga proses pengelolaannya masih membutuhkan waktu yang lumayan lama, karna sebelum itu kita harus pilah-pilah arsip terlebih dahulu sebelum di ketik secara manual dalam komputer.

Pengelolaan arsip secara manual sudah dari dulu sehingga menurut staf pengelolaan arsip ini seharusnya sudah diganti menjadi arsip digital, tapi pihak pemerintah belum merealisasikan hal tersebut. Pengelolaan arsip seharusnya lebih diperhatikan mengingat arsip sebagai bentuk informasi pentingdanpada saat ini sudah diera ITE yang dimanamana semua menggunakan aplikasi dan menggunakan sistem oneline.

c. Arsip dan Kearsipan

Arsip adalah rekaman kegiatan atau peristiwa dalam berbagai bentukdan media sesuai dengan perkembangan teknologi informasi dan komunikasi yang dibuat dan diterima oleh lembaga negara, pemerintah daerah, lembaga pendidikan, perusahaan, organisasi politik, organisasi kemasyrakatan dan perseorangan dalam pelaksanaan kehidupan bermasyarakat, berbangsa dan bernegara. (BPAD Provinsi SULSEL, 2010: 12) Telah diketahui kegunaan arsip adalah sebagai sumber informasi dan sebagai bahan pengingat oleh karna itu arsip yang mempunyai kegunaan atau nilainilai tertentu bagi organisasi harus disimpan agar setiap saat dapat dengan segera ditemukan kembali.

Kearsipan memegang peranan yang penting bagi kelancaran jalannyaorganisasi, yaitu sebagai sumber informasi dan sebagai pusat ingatan bagi organisasi Menurut Maulana (1974:18).

Fungsi arsip sangat penting menurut Widjaja yaitu sebagai sumber informasi dan dokumentasi. Sumber informasi membantu petugas mengingat mengenai suatu masalah, sumber dokumentasi bisa digunakan oleh pimpinan organisasi/instansi dalam mengambil suatu keputusan sebuah masalah.

Proses administrasi di kantor dinas perpustakaan dan kearsipan ini sudah cukup baik dan berjalan sesuai aturan yang berlaku pada Peraturan Pemerintah nomor 43 thn 2009 tentang kearsipan, Klarifikasi arsip dan aturan kepegawaian. Proses administrasi berjalan dengan baik dan tetap ikut dengan aturan yang berlaku namun perlu ditingkatkan untuk mencapai proses administrasi yang kebih efektif lagi.

Pengorganisasian, pelaksanaan dan pengaawasan dalam pengelolaan arsip sudah sesuai dengan bidang masing-masing pada dinas perpustakaan dan kearsipan. Pelaksanaan pengelolaan arsip sudah sesuai dengan peraturan pemerintah nomor 43 tahun 2009 tentang kearsipan.

Dari hasil penelitian yang dilakukan bahwa pengelolaan arsip dikantor Dinas Perpustakaan dan Kearsipan Kab. Polewali Mandar Peran pemerintah terhadap kearsipan saat ini kurang maksimal karna kurangnya anggaran tahunan yang di berikan oleh pemerintah untuk pengelolaan arsip lima tahun terakhir ini dari tahun ketahun semakin berkurang sehingga banyak agenda yang tidak terlaksana karna kurangnya anggaran, sosialisasi arsip dan perpustakaan kelilingpun berkurang di tahun 2019 hanya ada sedikit anggaran untuk pengelolaan arsip maupun untuk perpustakaan daerah sehingga membuat semua agendanya dikurangi, pembenahan arsip tidak banyak apalagi untuk perpustakaan. 


\section{SIMPULAN}

Kesimpulan berdasarkan pembahasan dan hasil penelitian dapat diambil kesimpulan bahwa:

1. Peran pemerintah terhadap pengelolaan arsip di Kantor Perpustakaan dan Kearsipan Kabupaten Polewali Mandar masih kurang perhatian dari pemerintah karena kurangnya anggaran beberapa tahun terakhir jadi tidak banyak kegiatan untuk perpustakaan terutama pengelolaan dan pembenahan kearsipan.

2. Proses administrasi sudah berjalan dengan baik sesuai dengan aturan, klarifikasi arsip dan aturan kepegawaian, beberapa proses kearsipan sudah sesuai dengan PP nomor 43 tahun 2009 dansudah lama di terapkan di kantor tersebut tapi ruang arsip belum memadai karna masih banyak arsip ditumpuk diatas meja, lemari dan tidak disimpan pada rak arsip, Pengelolaan arsip masih menggunakan sistem manual dengan cara mengetik setiap arsip yang masuk kedalam komputer.

Adapun saran yang dapat peneliti sampaikan berdasarkan kesimpulan diatas ialah:

1. Menambahkan sarana dan prasarana yang kurang seperti rak penyimpanan arsip, box arsip, lemari arsip dan perlu pembenahan agar ruang penyimpanan arsip lebih rapih, lebih luas, lebih terarur dan bersih lagi.

2. Lebih aktif untuk mensosialisasikan jika kerasipan itu sangat membantu. Harus meningkatkan pendekatan kepada OPD dan kecamatan agar selalu menyetorkan arsip tepat waktu agar kearsipan lebih baik lagi kedepannya.

3. Sudah saatnya arsip digital di era ITE.

4. Memasang CCTV diarea ruang penyimpanan agar arsip tetap terjaga dan aman.

5. Menambah tenaga khusus pengelolaan kearsipan.

\section{DAFTAR PUSTAKA}

\author{
Abubakar, Hadi. (1997). Cara-Cara Pengelolahan \\ Kearsipan yang Praktis dan Efisien. Jakarta: \\ Djambatan. \\ Bauer, J. C. (2003). A Comparison of Attitudes in \\ Germany and the United States. \\ Buku Pedoman Tata Surat Menyurat dan Kearsipan, \\ 1972
}

Maulana M. N (1974). Administrasi Kearsipan. Jakarta: Bharata.

Nurdin usman, (2002). Konteks implementasi berbasis kurikulum, Bandung: CV. Sinar Abru

Raho Bernard. (2007). Teori Sosiologi Modern. Jakarta: Prestasi Pusaka.

Bogdan dan taylor, (2012). Metodologi Penelitian Kualitatif. Bandung Remadja Karya

Soerjono Soekanto, (2009). Peranan Sosiologi Suatu Pengantar, Edisi Baru. Jakarta: Rajawali Pers.

Sedarmayanti, (2003). Tata Kearsipan dengan Memanfaatkan Teknologi Modern, cetakan ketiga. Bandung: Mandar Maju.

Sukandarrumidi. (2006). Metodologi Penelitian. Yogyakarta: Pers UGM.

Syaeba, M. (2019). PENGARUH EFISIENSI PENGELOLAAN KEARSIPAN TERHADAP PRODUKTIVITAS KERJA PEGAWAI DI KANTOR LURAH LANTORA KECAMATAN POLEWALI KABUPATEN POLEWALI MANDAR. MITZAL (Demokrasi, Komunikasi dan Budaya): Jurnal Ilmu Pemerintahan dan Ilmu Komunikasi, 2(1).

R. Terry George. (2006) Prinsip-prinsip Manajemen. Jakarta: Bumi aksara,

Rustan, I. R. (2019). PELAKSANAAN DAN FUNGSI PEMELIHARAAN ARSIP PADA DINAS KEARSIPAN DAN PERPUSTAKAAN DAERAH KABUPATEN MAMASA. MITZAL (Demokrasi, Komunikasi dan Budaya): Jurnal Ilmu Pemerintahan dan Ilmu Komunikasi, 3(1). 